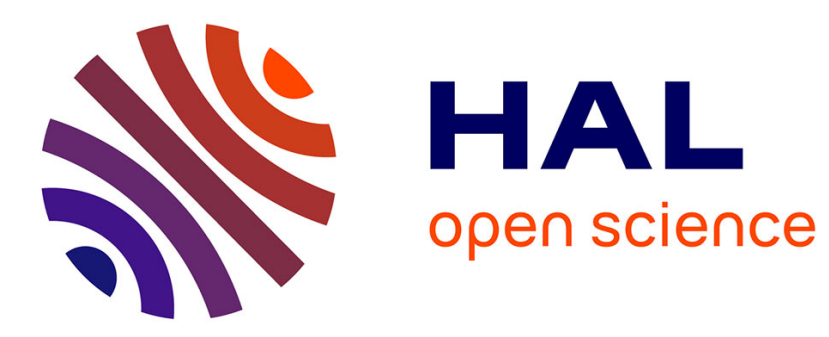

\title{
Producing undistorted acoustic sine waves
}

Henri Boutin, John Smith, Joe Wolfe

\section{To cite this version:}

Henri Boutin, John Smith, Joe Wolfe. Producing undistorted acoustic sine waves. Journal of the Acoustical Society of America, 2014, 10.1121/1.4868374] . hal-02470037

\section{HAL Id: hal-02470037 \\ https://hal.science/hal-02470037}

Submitted on 6 Feb 2020

HAL is a multi-disciplinary open access archive for the deposit and dissemination of scientific research documents, whether they are published or not. The documents may come from teaching and research institutions in France or abroad, or from public or private research centers.
L'archive ouverte pluridisciplinaire HAL, est destinée au dépôt et à la diffusion de documents scientifiques de niveau recherche, publiés ou non, émanant des établissements d'enseignement et de recherche français ou étrangers, des laboratoires publics ou privés. 


\title{
LETTERS TO THE EDITOR
}

This Letters section is for publishing (a) brief acoustical research or applied acoustical reports, (b) comments on articles or letters previously published in this Journal, and (c) a reply by the article author to criticism by the Letter author in (b). Extensive reports should be submitted as articles, not in a letter series. Letters are peer-reviewed on the same basis as articles, but usually require less review time before acceptance. Letters cannot exceed four printed pages (approximately 3000-4000 words) including figures, tables, references, and a required abstract of about 100 words.

\section{Producing undistorted acoustic sine waves $(\mathrm{L})$}

\author{
Henri Boutin, ${ }^{\text {a) }}$ John Smith, and Joe Wolfe \\ School of Physics, The University of New South Wales, Sydney, 2052, Australia
}

(Received 4 November 2013; revised 16 February 2014; accepted 20 February 2014)

\begin{abstract}
A simple digital method is described that can produce an undistorted acoustic sine wave using an amplifier and loudspeaker having considerable intrinsic distortion, a common situation at low frequencies and high power. The method involves, first, using a pure sine wave as the input and measuring the distortion products. An iterative procedure then progressively adds harmonics with appropriate amplitude and phase to cancel any distortion products. The method is illustrated by producing a pure $52 \mathrm{~Hz}$ sine wave at $107 \mathrm{~dB}$ sound pressure level with harmonic distortion reduced over the audible range to $>65 \mathrm{~dB}$ below the fundamental. (C) 2014 Acoustical Society of America. [http://dx.doi.org/10.1121/1.4868374]
\end{abstract}

PACS number(s): 43.58.Ry, 43.58.Vb [DAB]

Pages: $1665-1667$

\section{INTRODUCTION}

The distortion in audio electronics can usually be reduced to negligible amounts by careful design and the use of negative feedback. The situation for electromechanical transducers is quite different. Indeed producing undistorted acoustic sine waves is sometimes difficult, especially at low frequencies and high power, because of harmonic distortion, chiefly in the loudspeaker. Nevertheless, such signals are useful. The need that prompted this study was the investigation of subtle nonlinear behavior in a purely acoustic system, in which the nonlinearity was only observed at high power and low frequency. ${ }^{1}$ Although comparison of the harmonic content of the output with respect to the input can reveal the degree of distortion, such measurements become increasingly unreliable as the harmonic content of the input becomes dominant, hence, the need for an undistorted input. A similar comparison between input and output is not possible for psychophysical experiments. One example would be investigating the very low frequency response of the human ear: At frequencies below about $20 \mathrm{~Hz}$, the ear is very insensitive, so high power may be required, but at such frequencies some of the harmonic distortion would fall in the range where the ear is sensitive and potentially give false positive recognition.

For general signals, loudspeaker distortion can be substantially reduced using pre-distortion filters or active control. $^{2-4}$ For the particular, less demanding purpose of making a single, pure sine wave, this Letter reports a simple process that reduces the harmonic distortion near the position of the microphone by several tens of $\mathrm{dB}$.

\footnotetext{
a) Author to whom correspondence should be addressed. Electronic mail: henri.boutin@unsw.edu.au
}

\section{METHOD}

The initial signal generated by the computer is a sine wave denoted by $x_{0}(t)=e^{i \omega_{0} t}$ with unit amplitude and frequency, $\omega_{0}$. This signal passes through an audio interface, a power amplifier, a loudspeaker, an acoustic field, a microphone, a pre-amplifier, and the audio interface back to the computer. The complex loop gain (measured in a preliminary step at each harmonic, $k$, of interest with frequency, $\left.k \omega_{0}\right)$ is $G_{k} H_{k}$, where $G_{k}$ indicates the (complex) gain of the microphone and pre-amplifier and $H_{k}$ is the gain of the amplifier and loudspeaker. The signal returned to the computer after the first pass is $y_{0}(t)$,

$$
y_{0}(t)=H_{1}\left(G_{1} e^{i \omega_{0} t}+\sum_{k \geq 2} G_{k} \beta_{k} e^{i k \omega_{0} t}\right)
$$

where the coefficients $\beta_{k}$ indicate the harmonic distortion in the measured output returned to the computer when the input is a pure sine wave. The method consists of adding harmonics with appropriate magnitude and phase to the input in order to remove the harmonics in the output signal. The signal level at the speaker will be $\beta_{k} H_{1}$. To cancel the second harmonic in $y_{0}$, we divide the second component of its spectrum, $Y_{0}\left(2 \omega_{0}\right)$, by the gain, $G_{2} H_{2}$, and subtract it from $x_{0}$ giving a new signal $x_{1}(t)=e^{i \omega_{0} t}-\left(H_{1} / H_{2}\right) \beta_{2} e^{2 i \omega_{0} t}$. Then the output signal returned to the computer, $y_{1}$, is deduced from Eq. (1) to be

$$
\begin{aligned}
y_{1}(t)= & \left(G_{1} H_{1} e^{i \omega_{0} t}-G_{2} \beta_{2} H_{1} e^{2 i \omega_{0} t}\right)+G_{2} \beta_{2} H_{1} e^{2 i \omega_{0} t} \\
& + \text { terms of frequency } \geq 3 \omega_{0} .
\end{aligned}
$$

Its first component is unchanged. The first intermodulation product, in $2 \omega_{0}$, is cancelled by the corrective term, so 
that the next lowest component is in $3 \omega_{0}$. We iterate this method $N-1$ times,

$$
x_{n}=x_{n-1}-\sum_{k=2}^{n+1} \frac{Y_{n-1}\left(k \omega_{0}\right)}{G_{k} H_{k}} e^{i k \omega_{0} t},
$$

$(1 \leq n \leq N-1)$. Then, the harmonics added by the corrective term are all above $(N+1) \omega_{0}$. At the $n$th iteration, to calculate each corrective term, we calculate the spectrum of the output signal and measure $Y_{n-1}\left(k \omega_{0}\right)(2 \leq k \leq n+1)$. The values of $G_{k} H_{k}(2 \leq k \leq n+1)$ are also required to calculate each corrective term. To measure these values, sine waves of unit amplitude at frequency $k \omega_{0}(2 \leq k \leq N)$, are consecutively input in a preliminary step.

At the end of the procedure, the signal measured by the microphone has the distortion components removed. The microphone and the pre-amplifier have flat responses between $20 \mathrm{~Hz}$ and $20 \mathrm{kHz}$, and the audio interface has gain variations $<3 \%$ and a linear phase. Then, unless there is some extremely unlikely exact cancellation of distortion components somewhere within the loop, the output of the loudspeaker will also be undistorted.

\section{MATERIALS}

A computer is connected via a firewire audio interface (MOTU 828, Cambridge, MA) to a power amplifier (Brüel and Kjær, Denmark, model 2706) and a loudspeaker
(Peerless, Denmark) with a cone diameter of $155 \mathrm{~mm}$. The speaker is not enclosed and has no baffle; this reduces its efficiency at the fundamental and thus increases the relative harmonic distortion. A pressure-field microphone (1/4 in. Brüel and Kjær model 4944A) is positioned $50 \mathrm{~mm}$ from the center of the cone, initially on the axis of the loudspeaker. Its output is connected to the computer via a conditioning pre-amplifier (Brüel and Kjær Nexus type 2693) and the audio interface. Measurements are conducted in a room treated to reduce ambient noise and reverberation. Each iteration uses a sound sample of length $0.74 \mathrm{~s}$, compared with which the processing time is negligible, so $N$ iterations take $<N$ s.

\section{RESULTS}

The input signal is initially a pure sine wave of unit amplitude at the desired frequency; here, we chose $52.49 \mathrm{~Hz}$ so that none of its first 100 harmonics are multiples of $50 \mathrm{~Hz}$, the frequency of the mains in Australia. The amplifier gain is set to produce a sound level at the microphone of $107.4 \mathrm{~dB}$ with respect to $20 \mu \mathrm{Pa}$. Figure 1 shows three spectra. The first is that of the distorted sound recorded in the first measurement. Distortion is considerable; harmonics two to four are, respectively, $20 \mathrm{~dB}, 33 \mathrm{~dB}$, and $38 \mathrm{~dB}$ below the fundamental. The second shows the spectrum after three iterations; harmonics two to four are now between $66 \mathrm{~dB}$ and $67 \mathrm{~dB}$ below the fundamental, but the intermodulation products

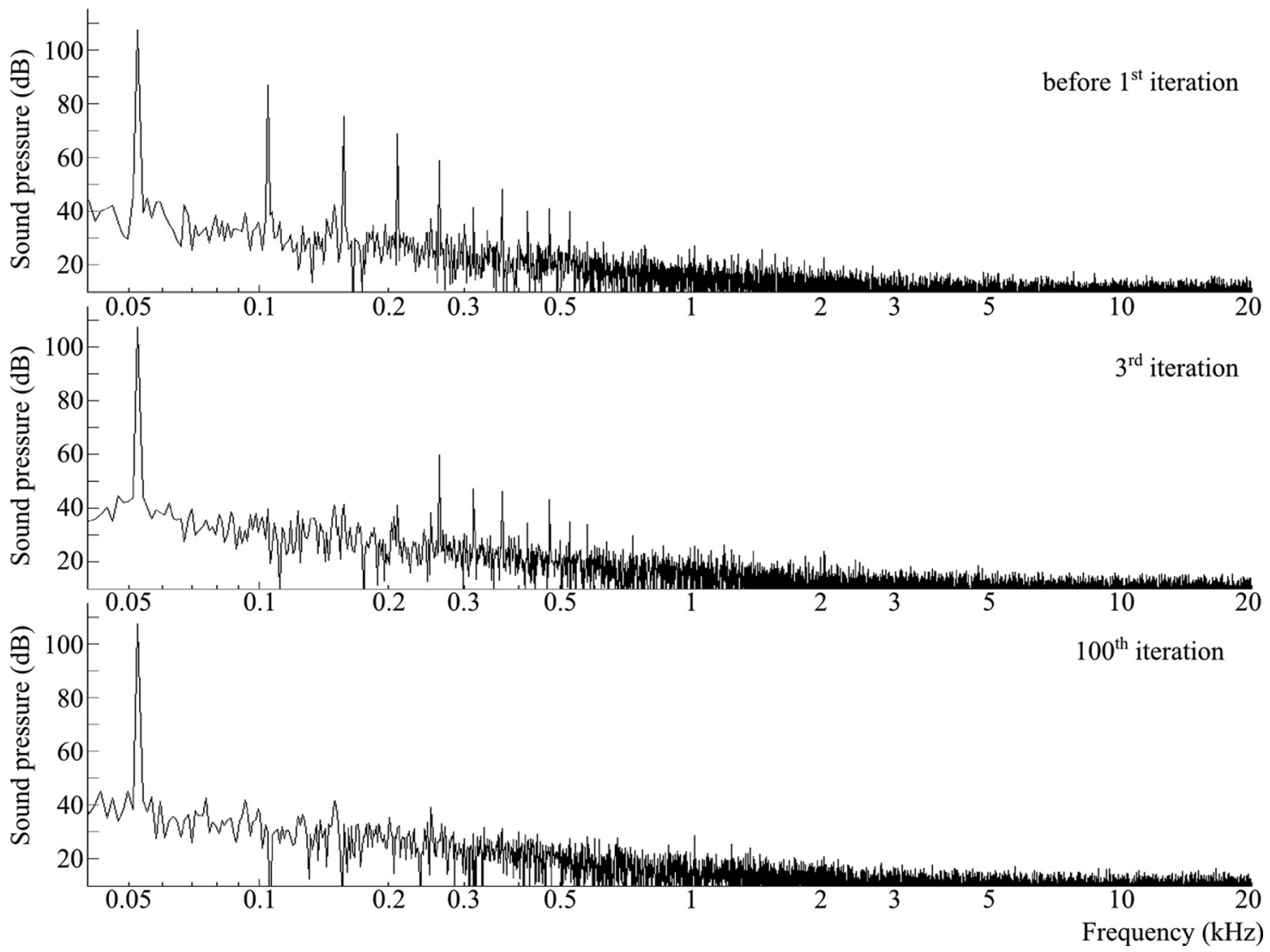

FIG. 1. The reduction of harmonic distortion by successive iterations. (a) The sound pressure spectrum (in dB with respect to $20 \mu \mathrm{Pa}$ ) recorded by the microphone when a pure sine wave at $52.49 \mathrm{~Hz}$ was input to the distorting system. (b) The result after three iterations. (c) After 100 iterations, all harmonics in the audible range have been reduced to $>65 \mathrm{~dB}$ below the fundamental. (The small peaks at 150 and $250 \mathrm{~Hz}$ are harmonics of mains interference, not harmonics of the signal.) 
have increased the power of some of higher harmonics. The third shows the result after 100 iterations. At this stage, all harmonics in the audible range have been reduced to be $>65 \mathrm{~dB}$ below the fundamental.

In this situation, since the loudspeaker itself generates negligible harmonic distortion above $\sim 5 \mathrm{kHz}, 100$ iterations were enough to reduce all harmonics in the audible range to a level comparable with the background noise.

This technique minimizes the distortion as measured by the microphone and if the microphone is located at the input of the acoustic device being investigated, the input will be undistorted, which suffices for the examples mentioned in the Introduction. In other locations, the possible presence of reflections and the inherent frequency dependence of the directivity of the loudspeaker can result in incomplete cancellation of the harmonic distortion.

For the demonstration in this paper, the microphone was located in the near-field radiation of a loudspeaker, which was unbaffled to increase its harmonic distortion, but which also increases the frequency dependence of its angular response. Up to $15^{\circ}$ off axis, the cancellation of harmonic distortion remained below $-60 \mathrm{~dB}$ for all harmonics. At larger angles, the correction signal sent to the speaker cannot compensate exactly for any nonlinear distortion that has strong angular dependence. For high harmonics, for which both distortion and correction terms have very small absolute magnitudes, variation of the distortion with angle has little effect on the ratio of harmonic to fundamental. For low harmonics, the distortion and, therefore, the correction terms are usually greater, so the absolute difference between distortion and cancellation becomes important. In our example, the second harmonic was $-20 \mathrm{~dB}$ with respect to the fundamental on axis and corrected to $-77 \mathrm{~dB}$. At $60^{\circ}$ off axis, distortion at the second harmonic is corrected from $-17 \mathrm{~dB}$ to only $-26 \mathrm{~dB}$, while distortion of the tenth and higher harmonics are corrected to $<-70 \mathrm{~dB}$.

In this paper, we have shown how to produce a pure acoustic sine wave; however, the method is readily applicable to any desired waveform.

\section{CONCLUSION}

This simple method demonstrated how to produce a pure sine wave with the amplitude of the harmonics in the audio range reduced to $65 \mathrm{~dB}$ or more below the amplitude of the fundamental.

\section{ACKNOWLEDGMENT}

We thank the Australian Research Council for support.

\footnotetext{
${ }^{1}$ J.-M. Chen, J. Smith, and J. Wolfe, "The effect of nearby timpani strokes on horn playing," J. Acoust. Soc. Am. 135, 472-478 (2014).

${ }^{2}$ F. X. Y. Gao and M. Snelgrove, "Adaptive linearization of a loudspeaker," in Proceedings of the IEEE International Conference on Acoustics, Speech and Signal Processing, ICASSP-91 (1991), pp. 3589-3592.

${ }^{3}$ W. J. Klippel, "Adaptive nonlinear control of loudspeaker systems," J. Audio Eng. Soc. 46, 939-954 (1998).

${ }^{4} \mathrm{~K}$. Lashkari, "A novel Volterra-Wiener model for equalization of loudspeaker distortions," in Proceedings of the IEEE International Conference on Acoustics, Speech and Signal Processing, ICASSP-06 (2006), Vol. 5, pp. V-117-V-120.
} 